\title{
Correspondence
}

\section{Shrinking biodiversity, dwindling taxonomy and building a broader science}

\author{
ART BORKENT \\ Research Associate, American Museum of Natural History, 691-8th Ave. SE, Salmon Arm, British Columbia, V1E 2C2, Canada; \\ "=artborkent@telus.net; @ https://orcid.org/0000-0002-5439-8793
}

In proposing what might be the three leading questions in taxonomy, I have thought primarily about what might be the biggest barriers to taxonomists accurately describing the species on our planet and interpreting their phylogenetic relationships within a historical context. I have generally used the vernacular and examples of issues which I know as a dipterist (fly taxonomist). I apologize to my colleagues working on other groups but hope to be pardoned in the recognition that the problems identified below do appear to apply to our broader taxonomic community.

\section{What are the impacts of the rapid rate of present day extinctions?}

As a society, we are experiencing the impacts of climate change on our communities and on natural systems. Combined with a further plethora of human-derived perturbations that include agri-business practices, other various land-use practices, acidification of oceans, pollution of air and water, water usage, and more, we are seeing huge and rapid changes. Based largely on vertebrate and plant studies, we are facing high levels of extinction. At the same time, as taxonomists we struggle to determine an approximate number of species on our planet, especially in the realm of entomologists and others working on smaller life forms. Approximately 1.9 million species of metazoan life have been named thus far (Chapman 2009) and estimates of the total number of insect species generally range from 1.8 to 10 million. Estimates of total metazoan life range from about 3 to 20 million in most papers (Borkent et al. 2018). The reality is that we have insufficient information. When a group of 59 dipterists (fly taxonomists) studied a 4 hectare patch of cloud forest in Costa Rica for one year, they discovered 4,332 species of flies, most of them undescribed but equal in number to half of all named fly species found in Central America and equal to $14 \%$ of all named Neotropical species (Borkent et. al. 2018; Brown et al. 2018). It is almost certain that a similar study in Guatemala, Colombia and Bolivia would produce equal or higher numbers of species, with most of them not shared between these sites. As forests continue to be cut at a high rate and wetlands continue to be drained or otherwise abused, there are many endemic species likely going extinct before we can even collect them.

Compounding this problem is that many of the areas protected by governments have become habitat islands surrounded by fields of wheat, soybeans, corn and other crops, or are isolated by other human occupations. Island populations are often prone to extinction (MacArthur \& Wilson 1967) and there is always the possibility of these isolated areas being completely wiped out by some extreme event (such as Australian wildfires). This dissected arrangement of biodiversity locations will almost certainly mean even higher rates of extinction in the near future.

Even in places where there are attempts to connect these islands of nature, there is a huge problem for this biodiversity. Studies of Pleistocene and Holocene fossils and subfossils in northern temperate regions (especially of beetles, plants, and vertebrates) have shown that communities in the past were often fundamentally different in composition than those present today (Elias 2010). For example, musk-ox bones have been found with oak (Quercus) and butternut pollen (Juglans cinerea) in 11,000 year old deposits in Michigan during the last ice age, even though today their ranges are separated by 1,500 $\mathrm{kms}$ (Semken et al. 1964). As such, it is clear that the responses of species to major environmental changes are for the most part not synchronized within communitiesother than those species which are intimately connected (e.g. parasites and hosts). The bulk of evidence indicates separate responses by different species. The idea of joining these human-generated islands of biodiversity through biocorridors which will allow some connection between these biodiversity islands, generally only applies to select (and mostly large) species such as vertebrates and many plants, not the bulk of the biodiversity present among smaller organisms. As such, climate change will likely mean that many species in habitat islands will have nowhere to go other than extinct. 
There are several consequences for taxonomists. One is that we will be missing a large number of species for most groups. There is good evidence that much has disappeared already among smaller organisms. For example, the denuded areas of the Andes almost certainly had endemic species that are no longer with us. Aside from a poorer understanding of overall diversity patterns (e.g. which lineages are more diverse than others), this will mean that many species with intermediate character states will be extinct and not known, increasing the odds of misinterpreting character state polarity in phylogenetic studies. Second, our goal of using phylogenetic information to interpret the zoogeography and bionomic divergence of lineages will be seriously undermined-increasingly driving taxonomists to make the sort of conjectures about missing lineages and states generally reserved for talking about missing fossil information. Finally, eliminating species destroys the evolutionary stories that give taxonomy so much of its impact in our broader societyspecies that show what evolution can do, in all of its bizarre and amazing divergence. We lament the extinction of the 14 species of moas in New Zealand and the species of elephants in North America in part because they would have bettered our understanding of what these lineages (e.g. ratite birds and proboscideans) could do. What is happening today is such an eradication of species in so many groups that we are literally eliminating hundreds of thousands (or more) of stories. These are the lost stories that taxonomists, in their capacity to describe species and their habitats, bionomics and phylogenetic relationships, would otherwise study and interpret in the future.

Combined with decreasing habitat availability is the general population decline of many groups - many species are becoming rarer. Therefore, along with various social and political considerations, it is increasingly difficult to obtain the means to study some biodiversity. Clearly, it is important to have detailed justification for collecting a rare mammal in a national park but the complexity of obtaining permits to collect various other groups, including many insects, is an increasing barrier to their study and certainly expensive in terms of time. It is peculiar to spend nearly a year obtaining a permit to collect biting flies that are being swatted and killed by others nearby. For many groups, the permit regulations implemented by bureaucracies are applied uniformly without knowledge of abundance or importance, because these groups are so poorly known to begin with.

At the same time, there is a general feeling of panic (or perhaps despair) among taxonomists that is driven by the need to collect as quickly as possible before more disappears - we know that we have little time to gather as much as possible before it is too late. This undermines a measured strategy of how best to describe species over the next hundreds of years as well as providing the necessary information to ensure their survival.

Numbers of taxonomists have written about and lamented the extinction of species currently underway. For example, 16 years ago Erwin (2004) wrote "Considering the potential benefits for humanity, not accomplishing an inventory of life on Earth has been the greatest failing of the human race so far. Or, perhaps, not even recognizing that such knowledge is fundamental to our long-term survival on Earth as a species is a greater failing". We now know the situation is even more dire.

Finally, every taxonomist I know has a measure of joy in knowing her/his group and the pattern of diversity present. We see pattern and beauty in our surroundings-I am reminded of a brilliant dipterist, Dick Vockeroth, who, while waiting at a bus stop in Ottawa, Canada, found a new species of fly bumping up against the protective glass. He brought it to work and gleefully explained where he had found it. As a group, we have a profound understanding of what biodiversity includes and the stories it presents, knowing how much it enhances our lives. The loss of biodiversity is a huge problem for taxonomists, but also is a huge loss to our society and future generations. We already have more than half the human family living in urban environments where children don't know the joy and freedom of walking along a forest trail or otherwise being in nature. For those of us who know what it means to be in nature - and especially to know so many species, this is to our collective loss and bodes poorly for the future of our societies. It is time for us as taxonomists to organize and generate the sort of collective message about declining biodiversity that the climate scientists have generated about climate change to our broader society.

\section{What is the future for taxonomists themselves?}

One of the amazing paradoxes present in our society is that there is a general recognition that biodiversity is under duress and with the expectation that many species, at least of vertebrates and many plants, are expected to disappear. And yet, concurrently, there is relatively little support for taxonomic studies and supporting institutions (museums/ collections) (Hoagland 1996, Lyal \& Weitzmann 2004, Ramsay 1986). Older taxonomists who have a broad understanding of their groups (morphologically, bionomically), a wealth of field experience, and a broader evolutionary context in which to interpret their knowledge, are retiring or have died. They are generally not being replaced (e.g. Natural History Museum, Britain). What used to be local working groups of taxonomists who could share with each other in a creative work space, have often been replaced by a single museum curator. A synthetic and compiling project that required a group effort such 
as the Manual of Nearctic Diptera was initially generated by a group of seven dipterists in Ottawa with a vision (Cumming et al. 2011). The manual was subsequently used as a model to produce similar volumes for most of the rest of the world. Such support and energy for similar projects in most groups of organisms, however, is currently scant and far between. Most remaining taxonomists are isolated and, like other biologists, scrambling (with many hours of labour) to compete for scarce grant funding. Field work is generally on a shoestring, few taxonomists have devoted technicians and artists to assist them directly, and there is an imposed need to justify working on a particular group in terms of immediate human needs. For example, the Ceratopogonidae (biting midges) is a large family with 6,205 described and more than 8,000 undescribed species, with rich natural history and the potential for amazing phylogenetic patterns, yet the odds of obtaining funding are increased by portraying the family mostly in terms of the less than $2 \%$ of species that bite humans and vector diseases.

One obvious consequence is that young taxonomists and potential students easily recognize that they cannot successfully compete on the basis of a comprehensive taxonomic understanding of a large group. Taxonomy positions are rare and sustainable funding to allow for longer term studies is virtually non-existent. There is little support for broad understanding and many recent positions are occupied by those who have skills in molecular analysis but limited understanding of the morphology and biology of the groups they have sequenced.

A training in taxonomy and its expanded form, systematics, should include a deep understanding of the taxonomic diversity of a wider group, morphology, palaeontology, geology, ecology, development, and, maybe, a philosophy course. These provide the tools to think deeply about what one observes and what it means in contemporary and historical terms. Yet, it is rare to meet a graduate student or recent graduate with such training. Further to this, in most instances, they don't have an environment to discuss and argue systematic themes with contemporaries because there are so few students who are explicitly doing graduate work in taxonomy, compared to the task at hand.

Therefore, at a time when we should, as a society, have an army of taxonomists studying biodiversity and providing information about the role of these species in our world, the training and secure hiring of taxonomists continues to decline in virtually every corner of the globe.

There are models of hope. In 1989 a group of forward thinking Costa Ricans ran an incredible experiment in developing an excellent basis for investigating and protecting their country's biodiversity. Instituto de Biodiversidad (INBio) was an institution with a mandate to sample and interpret species in Costa Rica. Initially, dozens of parataxonomists were selected (often with only a high school diploma) and trained to collect, curate, and identify to a certain level (often to genus), the taxa discovered. The training was provided largely by an international group of invited taxonomists. Hundreds of thousands of fresh specimens and thousands of new species came into the collection, along with detailed field information (and many observations of behaviour and habitat). Many foreign (and a few local) taxonomists incorporated material into their revisions and provided additional sophisticated training. Taxonomy boomed in that country. For example, one parataxonomist that I worked closely with, Annia Picado, could identify every family of fly on sight and, working with me on Ceratopogonidae, developed an amazing collection of tens of thousands of beautifully slide mounted specimens, which she could easily identify to genus. We co-authored papers on some genera, reflecting her skills and detailed knowledge. The model blossomed and INBio developed into a major museum with strong international connections. Combined with a drive to share and educate fellow citizens in Costa Rica, INBio was a model for the future and it appeared that every country in the world should have their own "INBio". Funding, however, became haphazard and eventually there were insufficient resources to keep the project going. Once the funding for INBio was reduced, one parataxonomist after another was painfully let go until INBio basically collapsed, with the collection taken over by Costa Rica's national museum. The highly skilled parataxonomists (about 40 at its height) mostly disappeared to do other unrelated jobs in their country and all that expertise in taxonomy was lost (some continue to be hired by Dan Janzen's project in Guanacaste). The national museum in Costa Rica now maintains the large collection on a shoestring and international connections have virtually disappeared. In spite of their financial issues, INBio remains a model of what can be accomplished; for many countries, a tourist tax of $\$ 3$ per person would be enough to sustain a functioning taxonomic/ biodiversity center.

As biodiversity disappears, the general lack of taxonomists to sample and interpret that diversity is a problem that will surely puzzle the next generations: "They knew about the biodiversity crisis but did little to study and protect it".

\section{What are some of the impacts of technology?}

There is little question that technology, and especially interactions with screens, has markedly changed our society. People in most corners of the globe can now access phone and internet services and all the information and potential they entail. In many instances there is an 
enhancement of lives (previously isolated Mayans in the highlands of Guatemala can now call for an ambulance in an instant). At the same time, there is a growing concern about how screen time modifies young brains. The American Academy of Paediatrics now recommends that no child below the age of 18 months should have any screen time other than limited video chatting, as more than this damages cognition, behaviour, and speech. Similarly, technology has been both a boon and a problem in taxonomy. Sophisticated means of photographing and measuring specimens, obtaining DNA sequence data, and analyzing the resultant data (morphological and molecular) have provided greater clarity in some ways but also present new challenges. There are two major arenas in which technology has radically changed our science: the definition of species and the interpretation of phylogenetic relationships. In both, there are some serious questions as to how the results truly reflect nature and/ or historical patterns of diversification.

DNA barcoding of species has swept through the biological community as a simple, cost-effective and apparently certain means of determining species. For example, DNA barcode libraries listing all species of Nearctic birds have been built and there is a great push to define the rest of life on the planet with this method. Barcoding is a powerful means of identifying species of well known groups and is clearly a boon to identifying not only large adult individuals but also partial remains, microscopic organisms, stomach contents, other life stages (larvae, pupae and adults), and dimorphic males and females. It also can provide a quick estimate of the number of species in a given area. Barcoding provides a real or apparent means of identification that does an end-run around the problem of finding and/or dealing with a taxonomic expert on the group. For groups that have a barcode library and well understood species, it provides real identifications, but for groups that do not, it provides only a sequence for a specimen that needs further study if anything more is to be understood about it. There lies the problem: "knowing" that there may be 94,000 species of insects in Canada (Hebert et al. 2016) is quite different than knowing those species by names that represent organisms in all of their complex morphology and biology and placed in a broader phylogenetic and ecological context. The apparent belief is that future taxonomists will be able to do the descriptive morphology and provide further interpretation on the basis of the voucher specimens that are housed in a collection somewhere (but often not curated and in poor condition). What is the value in having a list of sequences when it is not understood what those sequences actually represent in nature? Some variation in numbers of species in an area may be valuable in conservation biology but without knowing the actual species, there remains the question of whether such comparative numbers are a basis for making conservation decisions. In contrast, a taxonomic revision provides a wealth of knowledge about the group at hand, interpreting morphology, adaptations and biology of whole organisms in a real environment. For taxonomists who have field experience, there is the huge benefit of knowing what the various species are actually doing and where they are found - often the basis for allowing other biologists to investigate further.

Second, computer modeling has often interfered with a more detailed understanding of character states and how best to interpret them. Borkent (2018), Mooi \& Gill (2010), Williams et al. (2010) and others have detailed many of the issues underlying an unrestricted and simplistic use of programs and models to interpret character state distributions. A major concern is that outgroup comparisons are generally highly constricted and all character states are treated as equal. It ignores a reality in which every phylogenetically well-known group (with a good fossil record) includes only certain character states which provide the important synapomorphies indicating real historical relationships (e.g. equids, proboscideans). The problem of weighing character states is largely ignored, or if implemented, not thoroughly discussed in most publications.

Because the polarization of character states in most phylogenetic analyses are based on comparisons made with a minimalist outgroup (often 1-3 taxa), there is a poorer understanding of character state distributions. In reality, the character state distribution of one character may include all other members of the order (or more), while others with less information available may include only a few taxa in the potential outgroup. Regardless, broad outgroup comparisons allow for the identification of character states which are particularly prone to homoplasy (and often directly related to a common environmental factor) as compared to others which appear to be truly unique. These broader comparisons are no longer discussed in most taxonomic works. This reductionist approach makes it relatively easy to use the technology but at the cost of information that is important to our phylogenetic interpretation and communication if the weighing of character states is seen as a vital aspect of phylogenetic analysis. Using morphology, development, and function to weight character states are also no longer seen as necessary aspects of our analyses (and therefore no longer goals in the tool-kit of phylogenetic analysis). There is little incentive for most modern systematists to spend the time to understand the development and function of the character states they catalog.

For many in biology the panacea for phylogenetic analyses lies in molecular sequences and there is a steadily increasing number of non-taxonomists/systematists providing such analyses (often on the basis of one or a 
few genes). The methods are applied but not generally understood in any detail. The conclusions of molecular analyses are highly volatile even in groups where there are substantial morphological synapomorphies (e.g. Diptera), with results fluctuating over the years as further data became available. The promise has been that as more data become available, resolution will result, a promise that rarely works in science if the underlying principles are flawed. As a researcher without a detailed understanding of the programs analyzing sequence data (and very few do, even within that community), I can only see what the results appear to be-certain in their presentation but soon to be replaced. It has yet to be seen how sequence data can be reliably and consistently utilized in groups that are well known otherwise.

At the same time, there is a wealth of information presented by the evo/devo community on how phenotypes develop from a consortium of genes. The huge complexity derived from relatively few genes (e.g. humans have about 20,000) is reflected in how various structures are developed, with some based on one (or a few) genes and others with a varying group of genes throughout development. In short, some character states appear to be relatively easy to develop while others are more complex. In large measure the scientists working on sequences and those working on the genetic basis of morphological characters are divorced from one another. It is likely that some sequences are more important in indicating relationships than others. It remains largely unclear where the sequence data will lead us but if we want a fuller understanding of what they mean, the data will certainly need to be tied to the results of the evo/devo studies, and hence to the morphology and the polarization of character states.

Our goal as taxonomists should be to understand the nature of the characters we study, not only to understand how they distinguish species but also how best to interpret them phylogenetically. Hennig (1966) showed the way in distinguishing plesiomorphic and apomorphic characters; we have yet to develop a convincing methodology that best determines how to weigh apomorphic characters, determine which characters are homoplastic, and which characters are the best indicators of phylogenetic relationships.

\section{Acknowledgments}

My thanks, as always, to my wife Annette Borkent who supports my taxonomic work in so many ways, including financial. I am grateful for an earlier and helpful review by Chris Borkent as well as that of an anonymous reviewer.

\section{References}

Borkent, A. (2018) The state of phylogenetic analysis: narrow visions and simple answers-examples from the Diptera (flies). Zootaxa, 4374 (1), 107-143.

https://doi.org/10.11646/zootaxa.4374.1.7

Borkent, A., Brown, B.V., Adler, P.H., Amorim, D.S., Barber, K., Bickel, D., Boucher, S., Brooks, S.E., Burger, J., Burington, Z.L., Capellari, R.S., Costa, D.N.R., Cumming, J.M., Curler, G., Dick, C.W., Epler, J.H., Fisher, E., Gaimari, S.D., Gelhaus, J., Grimaldi, D.A., Hash, J., Hauser, M., Hippa, H., Ibáñez-Bernal, A., Jaschhof, M., Kameneva, E.P., Kerr, P.H., Korneyev, V., Korytkowski, C.A., Kung, G.-A., Kvifte, G.M., Lonsdale, O., Marshall, S.A., Mathis, W., Michelsen, V., Naglis, S., Norrbom, A.L., Paiero, S., Pape, T., PereiraColavite, A., Pollet, M., Rochefort, S., Rung, A., Runyon, J.B., Savage, J., Silva, V.C., Sinclair, B.J., Skevington, J.H., Stireman III, J.O., Swann, J., Vilkamaa, P., Wheeler, T., Whitworth, T., Wong, M., Wood, D.M., Woodley, N., Yau, T., Zavortink, T.J. \& Zumbado, M.A. (2018) Remarkable fly (Diptera) diversity in a patch of Costa Rican cloud forest: Why inventory is a vital science. Zootaxa, 4402 (1), 53-90. https://doi.org/10.11646/zootaxa.4402.1.3

Brown, B.V., Borkent, A., Adler, P.H., Amorim, D.S. de, Barber, K., Bickel, D., Boucher, S., Brooks, S.E., Burger, J., Burington, Z.L., Capellari, R.S., Costa, D.N.R., Cumming, J.M., Curler, G., Dick, C.W., Epler, J.H., Fisher, E., Gaimari, S.D., Gelhaus, J., Grimaldi, D.A., Hash, J., Hauser, M., Hippa, H., Ibáñez-Bernal, S., Jaschhof, M., Kameneva, E.P., Kerr, P.H., Korneyev, V., Korytkowski, C.A., Kung, G.A., Kvifte, G.M., Lonsdale, O., Marshall, S.A., Mathis, W., Michelsen, V., Naglis, S., Norrbom, A.L., Paiero, S., Pape, T., PereiraColavite, A., Pollet, M., Rochefort, S., Rung, A., Runyon, J.B., Savage, J., Silva, V.C., Sinclair, B.J., Skevington, J.H., Stireman, J.O. III, Swann, J., Thompson, F.C., Vilkamaa, P., Wheeler, T., Whitworth, T., Wong, M., Wood, D.M., Woodley, N., Yau, T., Zavortink, T.J., Zumbado, M.A. (2018) Comprehensive inventory of true flies (Diptera) at a tropical site. Communications Biology, 1 (21), 1-8. https://doi.org/10.1038/s42003-018-0022-x

Chapman, A.D. (2009) Numbers of living species in Australia and the world. 2nd Edition. Department of the Environment, Water, Heritage and the Arts, Australian Government, Canberra, 80 pp.

Cumming, J.M., Sinclair, B.J., Brooks, S.E., O’Hara, J.E \& Skevington, J.H. (2011) The history of dipterology at the Canadian National Collection of Insects, with special reference to the Manual of Nearctic Diptera. The Canadian Entomologist, 143, 539-577.

Elias, S.A. (2010) Advances in Quaternary entomology. Developments in Quaternary Science 12, Van der Meer, J.J.M. (Ed.), xiv $+288 \mathrm{pp}$.

Erwin, T.L. (2004) The biodiversity question: how many species of terrestrial arthropods are there? In: Lowman, M. \& Brinker, B. (Eds.), Forest canopies. Academic Press, London, pp. 259-269.

https://doi.org/10.1016/B978-012457553-0/50019-8

Hebert, P.D.N., Ratnasingham, S., Zakharov, E.V., Telfer, A.C., Levesque-Beaudin, V., Milton, M.A., Pedersen, S., Jannetta, P. \& de Waard, J.R. (2016) Counting animal species with DNA barcodes: Canadian insects. Philosophical Transactions of the Royal Society B, 371, 20150333. https://doi.org/10.1098/rstb.2015.0333 
Hennig, W. (1966) Phylogenetic systematics. Translated by Davis, D.D. \& Zangerl, R. University of Illinois Press, Urbana, Illinois, $280 \mathrm{pp}$.

Hoagland, K.E. (1996) The taxonomic impediment and the Convention of Biodiversity. Association of Systematics Collections Newsletter, 24 (5), 61-62, 66-67.

Lyal, C.H.C. \& Weitzmann, A.L. (2004) Taxonomy: exploring the impediment. Science, 305, 1106. https://doi.org/10.1126/science.305.5687.1106a

MacArthur, R.H. \& Wilson, E.O. (1967) The theory of island biogeography. Princeton Univ. Press, Princeton, New Jersey, xi +203 pp.

Mooi, R.D. \& Gill, A.C. (2010) Phylogenies without synapomorphies - a crisis in fish systematics: time to show some character. Zootaxa, 2450, 26-40.

https://doi.org/10.11646/zootaxa.2450.1.2

Ramsay, G.W. (1986) The taxonomic impediment to conservation. The Weta, 9 (2), 60-62.

Semken, H.A., Miller, B.B. \& Stevens, J.B. (1964) Late Wisconsin Woodland Musk Oxen in association with pollen and invertebrates from Michigan. Journal of Paleontology, 38, 823-835.

Williams, D.M., Ebach, M.C. \& Wheeler, Q.D. (2010) Beyond belief, the steady resurrection of phenetics. In: Williams, D.M. \& Knapp, S. (Eds.), Beyond cladistics: the branching of a paradigm. University of California Press, Berkeley/Los Angeles/London, pp. 169-195.

https://doi.org/10.1525/california/9780520267725.003.0010 